\title{
The Protective Role of Resilience in Emotional Exhaustion Among Dental Students at Clinical Levels
}

\author{
Alla Alsharif $(\mathbb{D}$ \\ Department of Preventive Dental \\ Sciences, Taibah University Dental \\ College and Hospital, Al-Madinah \\ Al-Munawwarah, Saudi Arabia
}

This article was published in the following Dove Press journal: Psychology Research and Behavior Management

Purpose: The epidemic of burnout among dental students has been repeatedly documented. This study aimed to assess burnout, specifically emotional exhaustion (EE), and examined the impact of protective and risk psychological factors for EE among clinical-level dental students in Saudi Arabia (SA).

Methods: A cross-sectional study was conducted, using a convenience sample of undergraduate dental students who were recruited from five separate dental schools. A selfadministered questionnaire was distributed to 500 students to obtain socio-demographic data and to assess the students' psychological characteristics (Maslach Burnout Inventory EE subscale, Dental Environment Stress Scale [DES] and Brief Resilience Scale [BRS]). Descriptive, bivariate and multivariable logistic regression analyses were performed.

Results: Of 272 respondents, 53\% reported high EE. Adjusted multivariable logistic regression modelling demonstrated that students who reported higher BRS scores were significantly less likely to report high $\mathrm{EE}$ (adjusted odds ratio $[\mathrm{AOR}]=0.79,95 \% \mathrm{CI}=0.70-0.89$, $\mathrm{p}<0.001)$. However, females were more than twice as likely as males to report high EE $(\mathrm{AOR}=2.27,95 \% \mathrm{CI}=1.14-4.61, \mathrm{p}=0.024)$. In addition, students who reported higher DES scores also reported high $\mathrm{EE}(\mathrm{AOR}=1.10,95 \% \mathrm{CI}=1.07-1.12, \mathrm{p}<0.001)$.

Conclusion: The findings suggest that resilience is a protective factor against high EE, after adjusting for key characteristics. There is a need for a preventive programme that addresses $\mathrm{EE}$, taking into consideration other unexplored underlying factors.

Keywords: burnout, emotional exhaustion, stress, dental, students, resilience

\section{Introduction}

Notably, dentists are among the health-care providers most prone to professional stress, burnout, anxiety and depression. ${ }^{1}$ Students who pursue careers in dentistry may experience occupational distress due to the nature of clinical practice management and interpersonal interaction competences. ${ }^{2,3}$ Psychological stress refers to an overload of mental, physiological and behavioural responses resulting from how individuals perceive situations or events in their environment. Based on previous studies, stress prevalence among Saudi undergraduate dental students ranges from $54 \%$ to $71 \%$ and intensifies with each progressive year that students study. ${ }^{4-7}$ Furthermore, multiple studies support the finding that stress influences burnout levels. ${ }^{4,6,8,9}$ Dental students at clinical levels can experience high levels of burnout, and this is related to dental programme requirements, which expose students to a combination of the risk factors of health workers (eg, dealing with and treating

Correspondence: Alla Alsharif

Department of Preventive Dental Sciences, Taibah University Dental College and

Hospital, Prince Naif Ibn Abdulaziz Road, Al-Madinah Al-Munawwarah 42353, Saudi Arabia

Tel +966504665331

Email dr-alsharif@hotmail.com 
patients) and those of university students (eg, academic commitments and exams). ${ }^{3,8,9}$ Recently, the epidemiology of burnout as an occupational phenomenon has become prominent. For example, the World Health Organization added burnout to the International Classification of Diseases (ICD) 10 and included more details in the ICD 11 (2019), defining burnout as "a syndrome conceptualised as resulting from chronic workplace stress that has not been successfully managed." ${ }^{\prime 10}$ Burnout is reported to be greater among health-care professionals, impacts personal and psychological health and social functioning and is often associated with low quality of work. ${ }^{11}$

Burnout is generally described by three dimensions: emotional exhaustion (EE); increased depersonalisation; and decreased personal accomplishments. ${ }^{12}$ The Maslach Burnout Inventory Survey Student (MBI-SS) is a wellknown measure of burnout among dental students, as it includes questions related to clinical and academic commitments. $^{8}$ A recent systematic review ${ }^{13}$ reported that the significant factors associated with burnout among dental students were as follows: age; gender; type of university (public or private); stress; and seniority level. The association between stress and burnout has also been documented among undergraduate dental students. ${ }^{14-16}$

A large body of literature has reported that $\mathrm{EE}$ is a critical element of burnout, and EE is the most widely reported and analysed dimension among the three subscales of burnout. ${ }^{1,16}$ This domain is described as a condition that results from excessive psychological demands, which can lead people to feel that their inner resources are becoming drained. ${ }^{17}$ Among dental students, EE is one of the most significant responses to stressful environmental stimuli, thus negatively impacting students' learning and clinical performance. ${ }^{3,18}$ The estimates of EE vary according to student seniority, sociocultural context and the MBI version used and has been reported to be $10-50 \%{ }^{3,10-14,19}$ Although research on factors associated with $\mathrm{EE}$ among dental students at the clinical level is scarce, the available and relevant literature has reported age, ${ }^{14}$ gender, ${ }^{16}$ university type $\mathrm{e}^{20}$ and environmental stress ${ }^{14,21,22}$ associated with EE. Generally, little attention has been given to the impact of protective factors on EE among dental students at clinical levels. The literature on psychosocial protective factors is mostly limited to nurses' resilience. ${ }^{23}$ In psychology, the term resilience has been defined in a number of ways, but it simply refers to the ability to bounce back or recover from stress, despite significant adversity. ${ }^{24,25}$ Interestingly, not all subscales of the MBI were associated with resilience characteristics (eg, mindfulness), suggesting that EE may be the most important target of intervention. ${ }^{26}$ Many studies (specifically on nurses) have shed light on the buffering effect of resilience on burnout (including EE), ${ }^{27,28}$ however, such a link among dental students has not been previously reported. A recent study by Smith et al only demonstrated that dental students reported relatively high levels of resilience. ${ }^{29}$ Nevertheless, in line with other studies, it is reasonable to assume that more resilient dental students would display fewer signs of EE, because repeated exposure to difficult academic situations and working environments would train dental students to overcome these difficulties and develop better coping mechanisms for stress.

Within the context of the present study, to date, there have been no studies conducted among dental students at clinical levels in Saudi Arabia (SA) to examine the relationships between $\mathrm{EE}$ and psychological protective and risk factors. This study aimed to assess the impact of protective and risk factors - specifically, dental environment stress and resilience - on EE among undergraduate clinical dental students in five dental schools in western SA. It was hypothesised that there would be no relationship between psychological experiences (eg, stress and resilience) and EE among clinical dental students.

\section{Materials and Methods Study Design, Setting and Sample Size Calculation}

This analytical cross-sectional study was conducted during the academic year 2017-2018 at five dental schools (public and private) in western SA. The dentistry curriculum in SA is unified and spans seven years, of which the first two are preclinical years and the remainder are clinical. The dentistry programmme recruits only Saudi national. The western region was chosen, as the researcher was affiliated with a number of professional groups at the region's dental colleges, who facilitated data collection. Students who were included in the study were at the clinical level and free from any health (physical/psychological) condition that would impede answering the questionnaire. Students at other levels of study (ie, levels one and two) were excluded from data analysis on the basis that these groups may have additional risk psychological factors (eg, anxiety) due to newly faced social and intellectual environments. ${ }^{30}$ 
The sample size was calculated using Epi Info StatCalc, considering a population size of 5000 dental students in the five dental schools and a 95\% confidence level, with expected frequency based on moderate and high burnout among relevant clinical students in SA of $65 \%,{ }^{31}$ with alpha error $=5 \%$. The calculated sample size was 327 .

\section{Recruitment of Participants, Data Collection Approach and Measures}

A convenience sample of students from five separate dental schools was recruited via student leaders, and the questionnaire was distributed between April and June 2018. The questionnaire included a covering page that explained the purpose of the study, confidentiality of the obtained data and institutional review board approval. In case of further queries, information about the researcher was also provided. The questionnaire asked about the covariates' socio-demographic characteristics, as well as explanatory psychological variables - specifically stress, burnout and resilience- - using validated inventories. The socio-demographic information included participants' gender, marital status, type of dental institute (private or public) and academic performance (grade point average [GPA]).

Each class leader distributed the questionnaire within their classes. The class leaders sent the anonymous questionnaire to potential participants using a direct link to a Google form, which was sent via WhatsApp messages. Upon completion of the questionnaire, respondents were instructed to simply submit the web form to the web server. The web server then transferred the data to Excel for storage and retrieval for analysis. The time needed to respond to the questionnaire was approximately 15 minutes.

\section{Measures}

\section{Academic Stress}

The students' stress (explanatory variable) was assessed using the Dental Environment Stress Scale (DES). ${ }^{20}$ This included questions about academic performance; difficulties and insecurities regarding students' professional future; responsibilities with patients; interpersonal relationships; and individual and institutional factors. Responses on each item were on a 4-point Likert-type scale (1: "not stressful at all"; 2: "somewhat stressful"; 3: "quite stressful"; and 4: "very stressful"). Validity of the clustered domains was evaluated quantitatively by factor analysis. $^{5}$

\section{Emotional Exhaustion}

Student EE, which was the outcome of interest (dependent variable), was assessed using the EE domain of the MBI-SS. This inventory is well established for the assessment of burnout ${ }^{12}$ and is based on 22 items that measure the three burnout components: "emotional exhaustion [EE]" with nine items; "depersonalisation [DP]" (or loss of empathy) with five items; and "personal achievement [PA]" with eight items. The responses on each item were on a 7-point Likert-type scale ranging from 0 to 6 (eg, 0: "Never"; 1: "A few times per day"). As noted, this study used the EE subscale to assess EE as a key component of burnout. The internal consistency reliability (Cronbach's alpha) of the original EE subscale is $0.90^{12}$ and, in various settings, including SA, has been found to range between 0.88 and $0.93 .{ }^{31-37}$ The factorial structure in the literature yielded one factor for the nine items of the EE subscale. With nine items, the scores for the EE subscale ranged from 0 to 54, categorised as low burnout $(\leq 16$, low EE), moderate burnout (17-26, moderate EE) and high burnout ( $\geq 27$, high EE). ${ }^{32}$ These three categories were dichotomised into high EE $(\geq 27)$ and not high EE $(<27) .{ }^{32,34}$

\section{Resilience}

Students' ability to bounce back or recover from stressful circumstances (resilience) was assessed using the Brief Resilience Scale (BRS). ${ }^{25}$ Resilience was used in this study as an explanatory variable. The scale consists of six items (eg, "I tend to bounce back quickly after hard times" and "I have a hard time making it through stressful events"). The responses to each item were on a 5-point Likert scale: $1=$ strongly disagree; $2=$ disagree; $3=$ neutral; $4=$ agree; 5=strongly agree. ${ }^{25}$ Negatively worded items were reverse scored before analysis. The BRS instrument has been validated in many previous studies. ${ }^{35}$ The Cronbach's alpha coefficient of the BRS scale reported elsewhere was $0.83 .{ }^{35}$

\section{Internal Consistency of EE, DES and BRS}

In this study, the internal consistency reliability (Cronbach's alpha) of the EE subscale (0.92) and DES (0.91) was excellent; that of the BRS (0.69) was acceptable. 


\section{Data Analysis}

The data was imported into the Statistical Package for the Social Sciences (IBM SPSS Statistics, Version 16, Armonk, NY, USA) for analysis. Descriptive statistics were calculated to report the sample's characteristics. Continuous variables were reported as median and interquartile range (IQR), as adherence to normality was not observed (Kolmogorov-Smirnov, $\mathrm{p}>0.05$ ), and the categorical variables were reported as frequencies with percentages (F [\%]). The psychometric properties (internal consistency reliability test [Cronbach's alpha]) of the dependent variable (burnout EE) and explanatory variables (DES and BRS) were assessed. The Cronbach's alpha estimates values in this study were interpreted according to Kline: ${ }^{30}$ acceptable $(0.60-0.69)$, good $(0.70-0.89)$ and excellent $(>0.90)$.

Bivariate analyses, chi-squared tests and Mann-Whitney $U$-tests were used to examine the association between the dependent variable and the explanatory variables and sociodemographic characteristics. Multivariable logistic regressions were used to examine the association of burnout EE with the significant factors found in the bivariate analyses. A significance level of $\mathrm{p}<0.05$ was used.

\section{Ethical Considerations}

The ethics committee of Taibah University Dental College and Hospital, Al-Madinah, SA, approved this study (TUCDREC/20,171,217/Al Madani). Completion and submission of the questionnaire were considered a proxy consent to participate. The study was conducted in accordance with the principles of the World Medical Association of Helsinki. Participation in the study was voluntary, and confidentiality of the information obtained was assured (ie, the questionnaire was anonymous and used non-identifying codes).

\section{Results}

\section{Response Rate and Participant Characteristics}

Of the 500 questionnaires sent to dental students, after accounting for non-responses and incomplete questionnaires, 272 (response rate $=83 \%$ ) usable questionnaires were submitted, including clinical students attending at public (224 [82.4\%]) and private (48 [17.6\%]) colleges. Of the total participating students at clinical levels, 53\% reported high EE. Table 1 shows the characteristics of the participants: the majority (71\%) were female, and $81 \%$ had a high level of academic performance. The median (range) scores of the EE, DES and BRS were $28(0-54)$, 77 (30-120) and 17 (7-27), respectively.

\section{Emotional Exhaustion and Its Associated Factors}

In bivariate analysis (Table 1), female students, academic performance (GPA) and students with higher stress scores reported statistically significantly higher EE $(p<0.001$, 0.044 and $<0.001$, respectively). Conversely, higher resilience scores were significantly inversely related to high EE $(\mathrm{p}<0.001)$.

As shown in Table 2, three variables (gender, DES and BRS) that emerged from the bivariate analyses made a statistically significant contribution to the adjusted logistic regression model. Namely, females were 2.27 (95\% $\mathrm{CI}=1.14-4.61 ; \mathrm{p}=0.024)$ times more likely to self-report high $\mathrm{EE}$ than were males, and higher DES scores were associated with high $\mathrm{EE}(\mathrm{OR}=1.10,95 \% \mathrm{CI}=1.07-1.12$, $\mathrm{p}<0.001)$. Also, BRS was inversely associated with high EE (ie, students who reported high levels of resilience were less likely to report high $\mathrm{EE}(\mathrm{OR}=0.79$, 95\% $\mathrm{CI}=0.70-0.89 ; \quad \mathrm{p}<0.001)$ ). This regression model explained between 39\% (Cox \& Snell R Square) and $52 \%$ (Nagelkerke R Square) of the variance in high EE.

\section{Discussion}

In the present study, high EE was reported by a significant percentage of clinical-level dental students in the 20172018 academic year in western SA and was associated with gender, dental environment stress and resilience. The proportion of the dental clinical students who reported high EE was significant, which is consistent with previous studies. ${ }^{3,13}$

The high percentage of participants with high EE in the sample may be due to the sociocultural context of the study and the cut-off adopted for discriminating high and low EE. For the significant demographic factor-genderhigher EE levels were reported by females in our study, which is consistent with a study by Kulkarni et al, ${ }^{21}$ but conflicts with results for males and females in other studies. ${ }^{13}$ Our findings may indicate that there is pressure on females to either equal or outperform their male counterparts to prove their value in a male-dominated field. It is also important to note that most of the participants were female $(71 \%)$, which reflects gender trends at dental 
Table I Total Sample Characteristics and Bivariate Analysis of High Emotional Exhaustion with the Socio-Demographics and BRS and DES Among Clinical Dental Students in Five Colleges at West of Saudi Arabia, Academic Year 20I7-2018 (N=272)

\begin{tabular}{|c|c|c|c|c|}
\hline \multicolumn{2}{|l|}{ Variables } & \multirow{2}{*}{$\begin{array}{l}\text { Whole Sample F (\%)/Median(IQR) } \\
79(29.0) \\
193(71.0)\end{array}$} & \multirow{2}{*}{$\begin{array}{l}\text { High EE } \\
\text { F (\%)/Median(IQR) } \\
26(32.9) \\
118(61.1)\end{array}$} & \multirow{2}{*}{$\begin{array}{l}P \text {-value } \\
<0.00 \text { I }\end{array}$} \\
\hline Sex & $\begin{array}{l}\text { Males } \\
\text { Females }\end{array}$ & & & \\
\hline Marital status & $\begin{array}{l}\text { Single } \\
\text { Married }\end{array}$ & $\begin{array}{l}249(91.5) \\
23(8.5)\end{array}$ & $\begin{array}{l}|3|(52.6) \\
13(56.5)\end{array}$ & 0.262 \\
\hline Residency & $\begin{array}{l}\text { With family } \\
\text { Elsewhere }\end{array}$ & $\begin{array}{l}236(86.8) \\
36(13.2)\end{array}$ & $\begin{array}{l}124(52.5) \\
20(55.6)\end{array}$ & 0.736 \\
\hline University sector & $\begin{array}{l}\text { Public } \\
\text { Private }\end{array}$ & $\begin{array}{l}224(82.4) \\
48(17.6)\end{array}$ & $\begin{array}{l}116(51.8) \\
28(58.3)\end{array}$ & 0.410 \\
\hline Academic performance & $\begin{array}{l}\text { High } \\
\text { Low }\end{array}$ & $\begin{array}{l}220(80.9) \\
52(19.1)\end{array}$ & $\begin{array}{l}123(55.9) \\
21(40.4)\end{array}$ & 0.044 \\
\hline Re-sit a year in dental school & $\begin{array}{l}\text { Yes } \\
\text { No }\end{array}$ & $\begin{array}{l}45(16.5) \\
227(83.5)\end{array}$ & $\begin{array}{l}23(51.1) \\
12 \mid(53.3)\end{array}$ & 0.788 \\
\hline DES & & $76.50(30-120)$ & $\begin{array}{l}\text { High value of } E E=86.0 \\
\text { Low value of } E E=65.0\end{array}$ & $<0.001$ \\
\hline BRS & & $17.00(7-27)$ & $\begin{array}{l}\text { High value } E E=16.50 \\
\text { Low value } E E=18.00\end{array}$ & $<0.001$ \\
\hline
\end{tabular}

Note: ${ }^{a}$ Chi-squared and Mann Whitney U-Tests used for comparisons of proportions and correlation.

Abbreviations: EE, emotional exhaustion; DES, Dental Environmental Stress; BRS, Brief Resilience Scale.

Table 2 Logistic Regression Predicting Likelihood of Self-Reporting High Emotional Exhaustion Among Clinical Dental Students in Five Colleges at West of Saudi Arabia, Academic Year, 2017-2018 ( N=272)

\begin{tabular}{|c|c|c|c|c|}
\hline Explanatory Variables & B & Wald & AOR $(95 \% \mathrm{Cl})$ & p-Value \\
\hline $\begin{array}{l}\text { Sex } \\
\text { Male (ref) } \\
\text { Female }\end{array}$ & 0.818 & 5.10 & $\begin{array}{l}- \\
2.27(1.14-4.61)\end{array}$ & 0.024 \\
\hline $\begin{array}{l}\text { Academic performance } \\
\text { High (ref) } \\
\text { Low }\end{array}$ & 0.395 & 0.837 & $\begin{array}{l}- \\
1.48(0.64-3.46)\end{array}$ & 0.360 \\
\hline $\begin{array}{l}\text { DES } \\
\text { BRS }\end{array}$ & $\begin{array}{l}0.091 \\
-0.235\end{array}$ & $\begin{array}{l}48.81 \\
14.72\end{array}$ & $\begin{array}{l}1.10(1.07-1.12) \\
0.79(0.70-0.89)\end{array}$ & $\begin{array}{l}<0.001 \\
<0.001\end{array}$ \\
\hline
\end{tabular}

Abbreviations: B, Unstandardized coefficients; AOR, adjusted odds ratio; $95 \% \mathrm{Cl}$, confidence interval; DES, Dental Environmental Stress; BRS, Brief Resilience Scale.

schools over recent decades, as has been previously reported. $^{36}$

Both the DES and BRS were found to be significantly associated with self-reported high EE, consistent with previous studies. ${ }^{19,21}$ Therefore, the null hypothesis proposed in this study was rejected. Our model revealed that the higher the stress levels dental students displayed, the higher the risk of EE. It has previously been established that the intensity of stress and burnout for dental students tends to escalate over time, peaking in the senior years of training. ${ }^{6}$ Although this study found that resilience (BRS) was significantly inversely related to $\mathrm{EE}$, due to the paucity of research on the relationship between resilience and EE in dental students, it is difficult to compare our findings with similar studies. However, many researchers have investigated nurses' cognitive and behavioural responses to stressful situations and have found that nurses with low resilience are more likely to experience high EE. ${ }^{37}$ 
The strengths of this study are the use of well-established inventories to assess EE, DES and BRS; and the consistency of the dental curriculum in SA, so the results of the study are less likely to reflect curriculum diversity. However, a number of limitations could have influenced the results obtained. Namely, cross-sectional data cannot be used to infer causality, as temporality is not known. Also, the self-report format and the selfselection of participants completing the questionnaire could have biased the results. Age data were also not collected, but the clinical level of dental training was considered a proxy for age, as students at this level are usually aged between 21 and 23 years. Only demographics and academic stressors that have previously been reported as major, along with common factors influencing EE, were assessed. Finally, the convenience sample of this study precludes generalisability of the findings. Replication of our findings in a representative sample of dental students at clinical levels, together with an exploration of a number of personal traits (eg, personality type, self-efficacy and emotional intelligence) may add additional details to the dynamics of EE.

\section{Conclusions}

Within the limitation of this study, the findings suggest that resilience was a protective factor, while DES was a risk factor for EE. Notably, females were more likely to report high EE. There is a need for preventive programmes to address EE, taking into consideration the abovementioned and other underlying factors.

\section{Data Sharing Statement}

Data are available by contacting Alla Alsharif.

\section{Acknowledgments}

I would like to thank Saba Kassim from Taibah University Dental College and Hospital for her critical comments on the manuscript. Also, the role of Mohammed Alturki, Mohammed Albedaiwi, Rawan Mahmoud and Noral AlMadani in data collection is acknowledged likewise the participating students in the study.

\section{Funding}

This research received no specific grant from any funding agency in the public, commercial, or not-for-profit sectors.

\section{Disclosure}

The author declared no potential conflicts of interest.

\section{References}

1. Cooper C, Watts J, Kelly M. Job satisfaction, mental health, and job stressors among general dental practitioners in the UK. Br Dent $J$. 1987;162(2):77-81. doi:10.1038/sj.bdj.4806030

2. Blinkhorn A. Stress and the dental team: a qualitative investigation of the causes of stress in general dental practice. Dent Update. 1992;19 (9):385-387.

3. Jiménez-Ortiz J, Islas-Valle R, Jiménez-Ortiz J, Pérez-Lizárraga E, Hernández-García ME, González-Salazar F. Emotional exhaustion, burnout, and perceived stress in dental students. J Int Med Res. 2019;47(9):4251-4259. doi:10.1177/0300060519859145

4. Al-Saleh S, Al-Madi E, Al-Angari N, Al-Shehri H, Shukri M. Survey of perceived stress-inducing problems among dental students, Saudi Arabia. Saudi Dent J. 2010;22(2):83-88. doi:10.1016/j.sdentj.2010.02.007

5. Al-Sowygh Z, Alfadley A, Al-Saif M, Al-Wadei S. Perceived causes of stress among Saudi dental students. J Dent Sci. 2012;4(1):7-15.

6. Al-Sowygh Z. Academic distress, perceived stress and coping strategies among dental students in Saudi Arabia. Saudi Dent J. 2013;25 (3):97-105. doi:10.1016/j.sdentj.2013.05.002

7. Basudan S, Binanzan N, Alhassan A. Depression, anxiety and stress in dental students. Int $J$ Med Educ. 2017;8:179-186. doi:10.5116/ ijme.5910.b961

8. Subirats-Roig C, Flores-Martí P, Bellot-Arcís C, Almerich-Silla JM. Validation of the maslach burnout inventory-human services survey for estimating burnout in dental students. J Dent Educ. 2016;80 (11):1368-1375. doi:10.1002/j.0022-0337.2016.80.11.tb06222.x

9. Pöhlmann K, Jonas I, Ruf S, Harzer W. Stress, burnout and health in the clinical period of dental education. Eur J Dent Educ. 2005;9 (2):78-84. doi:10.1111/j.1600-0579.2004.00359.x

10. World Health Organization. Burn-Out an 'Occupational Phenomenon': International Classification of Diseases. WHO; 2019.

11. Bullock G, Kraft L, Amsden K, et al. The prevalence and effect of burnout on graduate healthcare students. Can Med Educ J. 2017;8(3): e90. doi:10.36834/cmej.36890

12. Maslach C, Jackson SE, Leiter M. The Maslach Burnout Inventory Manual. 3rd ed. Palo Alto, CA: Consulting Psychologies Press; 1996.

13. Singh P, Aulak DS, Mangat SS, Aulak MS. Systematic review: factors contributing to burnout in dentistry. Occup Med. 2015;66 (1):27-31. doi:10.1093/occmed/kqv119

14. Divaris K, Polychronopoulou A, Taoufik K, Katsaros C, Eliades T. Stress and burnout in postgraduate dental education. Eur J Dent Educ. 2012;16(1):35-42. doi:10.1111/j.1600-0579.2011.00715.x

15. De Lourdes Preciado-serrano M, Vazquez-Goni JM. Stress profile and burnout syndrome in Mexican dental students of a public university. Rev Chil Neuropsiquiatr. 2010;48(1):11-19.

16. Divaris K, Lai CS, Polychronopoulou A, Eliades T, Katsaros C. Stress and burnout among Swiss dental residents. Schweiz Monatsschr Zahnmed. 2012;122(7-8):610-615.

17. Te Brake H, Smits N, Wicherts JM, Gorter RC, Hoogstraten J. Burnout development among dentists: a longitudinal study. Eur J Oral Sci. 2008;116(6):545-551. doi:10.1111/j.1600-0722.2008.00584.x

18. Alzahem A, van der Molen H, Alaujan A, et al. Stress amongst dental students: a systematic review. Eur J Dent Educ. 2011;15(1):8-18. doi:10.1111/j.1600-0579.2010.00640.x

19. Jin MU, Jeong SH, Kim EK, Choi YH, Song KB. Burnout and its related factors in Korean dentists. Int Dent J. 2015;65(1):22-31. doi:10.1111/idj.12142

20. Humphris G, Blinkhorn A, Freeman R, et al. Psychological stress in undergraduate dental students: baseline results from seven European dental schools. Eur J Dent Educ. 2002;6(1):22-29. doi:10.1034/ j.1600-0579.2002.060105.x 
21. Kulkarni S, Dagli N, Duraiswamy P, Desai H, Vyas H, Baroudi K Stress and professional burnout among newly graduated dentists. $J$ Int Soc Prev Community Dent. 2016;6(6):535-541. doi:10.4103/ 2231-0762.195509

22. Asghar A, Faiq A, Shafique S, et al. Prevalence and predictors of the burnout syndrome in medical students of Karachi, Pakistan. Cureus. 2019;11(6):e4879.

23. Foster RN, Roche M, Delgado C, Cuzzillo C, Giandinoto JA, Furness T. Resilience and mental health nursing: an integrative review of international literature. Int J Ment Health Nurs. 2019;28(1):71-85. doi:10.1111/inm. 12548

24. Tusaie K, Dyer J. Resilience: a historical review of the construct. Holist Nurs Pract. 2004;18(1):3-10. doi:10.1097/00004650-200401000-00002

25. Carver C. Resilience and thriving: issues, models, and linkages. J Soc Issues. 1998;54(2):245-266.

26. Olson K, Kemper K, Mahan J. What factors promote resilience and protect against burnout in first-year pediatric and medicine-pediatric residents? J Evid Based Complement Alternat Med. 2015;20:192198. doi:10.1177/2156587214568894

27. Anasori E, Bayighomog S, Tanova C. Workplace bullying, psychological distress, resilience, mindfulness, and emotional exhaustion. Serv Ind J. 2020;40(1):65-89. doi:10.1080/02642069.2019.1589456

28. Choi B, Kim J, Lee D, et al. Factors associated with emotional exhaustion in South Korean nurses: a cross-sectional study. Psychiatry Investig. 2018;15(7):670-676. doi:10.30773/pi.2017.12.31

29. Smith C, Carrico C, Goolsby S, Hampton A. An analysis of resilience in dental students using the resilience scale for adults. J Dent Educ. 2020;84(5). doi:10.1002/jdd.12041
30. Bayram N, Bilgel N. The prevalence and socio-demographic correlations of depression, anxiety and stress among a group of university students. Soc Psychiatry Psychiatr Epidemiol. 2008;43(8):667-672. doi: 10.1007/s00127-008-0345-X

31. Aldubai S, Aljohani A, Alghamdi A, Alghamdi K, Ganasegeran K, Yenbaawi A. Prevalence and associated factors of burnout among family medicine residents in Al Madina, Saudi Arabia. J Family Med Prim Care. 2019;8(2):657. doi:10.4103/jfmpc.jfmpc_268_18

32. Beckstead J. Confirmatory factor analysis of the maslach burnout inventory among Florida nurses. Int J Nurs Stud. 2002;39(8):785792. doi:10.1016/S0020-7489(02)00012-3

33. Al-Dubai S, Ganasegeran K, Perianayagam W, Rampal K. Emotional burnout, perceived sources of job stress, professional fulfilment, and engagement among medical residents in Malaysia. ScientificWorldJournal. 2013;2013:9. doi:10.1155/2013/137620

34. Smith B, Dalen J, Wiggins K, Tooley E, Christopher P, Bernard J. The brief resilience scale: assessing the ability to bounce back. Int $J$ Behav Med. 2008;15(3):194-200. doi:10.1080/10705500802222972

35. Rodriguez-Rey R, Alonso-Tapia J, Hernansaiz-Garrido H. Reliability and validity of the brief resilience scale (BRS) Spanish version. Psychol Assess. 2016;28(5):e101-e110. doi:10.1037/pas0000191

36. Shaker R, Babgi A. Women in dentistry: a perspective on major universities in Saudi Arabia. Part 2: analysis and statistical data. Saudi Dent J. 2009;21(3):107-112. doi:10.1016/j.sdentj.2009.03.002

37. Gillespie B, Chaboyer W, Wallis M, Grimbeek P. Resilience in the operating room: developing and testing of a resilience model. $J$ Adv Nurs. 2007;59(4):427-438. doi:10.1111/j.1365-2648.2007.04340.x
Psychology Research and Behavior Management

\section{Publish your work in this journal}

Psychology Research and Behavior Management is an international, peer-reviewed, open access journal focusing on the science of psychology and its application in behavior management to develop improved outcomes in the clinical, educational, sports and business arenas. Specific topics covered in the journal include: Neuroscience, memory and decision making; Behavior modification and management; Clinica applications; Business and sports performance management; Social and developmental studies; Animal studies. The manuscript management system is completely online and includes a very quick and fair peer-review system, which is all easy to use. Visit http://www. dovepress.com/testimonials.php to read real quotes from published authors. 